\title{
FAMILY PRACTICES ACROSS GENERATIONS AND NATIONAL BORDERS
}

\author{
IONUȚ FÖLDES 1 AND VERONICA SAVU²
}

\begin{abstract}
Part of the mobility and migration process, family relationships and mutual support are subject of various transformations. Spatial separation between family members creates a specific setting for analysis which leads to the necessity of understanding how family practices are arranged and developed across time and distance. The present study focuses on the dyad emigrated adult children and non-migrated elderly parents living in Romania and on the types of intergenerational family practices that occur between these dyads across national borders. Our analysis of family practices relies on tracing certain set of actions taken by family members in order to maintain, consolidate, and ultimately to display family solidarity. We consider here various forms of practices, namely technological mediated contacts, visits, time-consuming practical support and financial assistance. Analyses are based on the national survey entitled Intergenerational solidarity in the context of work migration abroad. The situation of elderly left at home, which provides empirical data about the relationships from a distance between elderly parents living in Romania and their migrant adult children. Descriptive statistics are provided in order to assess the flow directions, the frequency and the intensity of each type of intergenerational support. Our empirical evidence highlights that transnational support is asymmetrical and multidirectional. Results also support that intergenerational support and family relationships can no longer be theoretically approached in terms of a simple dichotomy.
\end{abstract}

Keywords: family practices, circulation of care, intergenerational relationships, transnational families, migration

\footnotetext{
${ }_{1} \mathrm{PhD}$ Candidate in Sociology at the Babeș-Bolyai University Cluj-Napoca, e-mail: ionut.foldes@gmail.com.

2 PhD Candidate in Sociology at the Babeș-Bolyai University Cluj-Napoca, e-mail:veronica.somesan@yahoo.com.
} 


\section{Introduction ${ }^{3}$}

The phenomenon of increased mobility and international migration has become a common feature of the contemporary Romanian social context and it also captured the attention of numerous researchers. Romanian citizens represent the largest ethnical minority in Spain, Italy and Hungary, while in the case of other European countries, such as Germany, France or UK, Romania is among the most important sending countries. According to Eurostat (2018), around $20 \%$ of the working age (20-64) Romanian population lives in another European Union member state. Worldwide, Romania is the $16^{\text {th }}$ country with the largest diaspora population (UN, 2017). Research has been carried out in order to assess the motivations for migration or the intentions of returning, to investigate migration trajectories, migration networks, migration typologies or migration regimes and to evaluate the economic impact of remittances. Regarding the family, early studies focused on the underage children left in Romania or on family reunification abroad. However, our research investigates the relationship between families and international migration from a different analytical angle, expanding the focus from the nuclear family towards the extended families and intergenerational linkages. By relying on nation-wide survey data, we can capture a broader picture of the phenomena while highlighting both the positive as well as the less encouraging outcomes of Romanian transnational family life. The study's final goal is to conceptualise our empirical findings within the international literature on transnational families.

In the present paper we focus on a very particular type of family relationships, namely between emigrant adult children and their ageing parents living in Romania. Without relying on the use of any normative prescribed roles, our contribution aims to address the importance of family relationships in adult life. For this purpose, our approach enlarges the concept of family and goes beyond the nuclear family unit and across distance. The usage of the word family is not intended to define what family means, but rather to try and understand family as a form of action - doing family (Morgan, 2011). Therefore, we translate family relationships as a specific social process which includes a set of interactions holding different meanings and taking place in a setting which, to some degree, is subject to variation. The specificity of this type of relationships comes from a complex set of cultural, economic and historical factors which shape the values, expectations, behaviours and more importantly, the

\footnotetext{
3 This work has been supported by a grant of the Romanian National Authority for Scientific Research and Innovation, CNCS - UEFISCDI, project number PN-II-RU-TE-2014-4-1377.
} 
readjustments towards and within the family. Morgan's $(1996,2011)$ concept of family practices captures very well our stand point for this study. The author alleges that family practices are 'reflective practices; in being enacted they simultaneously construct, reproduce family boundaries, family relationships and possibly more discursive notions of the family in general' (Morgan, 2011: 163).

From a relational family arrangements perspective, our contribution aims to assess the intensity and variety of family practices across generations and national borders. By doing so, we address a critique of Parsons' functionalist perspectives (Parsons, 1951) and of the recent individualization perspectives (see for example Giddens, 1992, 1994). Due to the nature of our empirical data, we have the possibility to provide a much broader image of family practices in a transnational setting, including both positive and less positive outcomes. Therefore, our analytical inquiry is guided by several questions. Can we locate family and family-like intergenerational relations in a wider spatial setting than the household and national borders? Does the individualization process erode family ties and suppress the collectivistic nature of family relationships? Does the broken vs. solid dichotomy properly explain intergenerational family relationships? Can we discuss about a general high dependency ratio between generations at the family level? Starting with these questions, in the next section we try to highlight how family practices are subject to variations while addressing the issue of geographical separation and living across national borders. Later, we will discuss our data source and methodological approach. Following that, a vast quarter of this paper will focus on displaying our empirical evidences and discussing the theoretical gains of the results. As it will be made clear in the following sections, our results have a great descriptive quality. The intention here was not to address any causal statistical relationships but rather to provide a straightforward and insightful image of family practices across generations and national borders.

\section{Confronting distance and separation}

New studies on transnationalism and families living separated by national borders point out the fact that support exchanges within kinship networks are not restricted to geographical proximity. Early evidence suggests that across all forms of scour, spatial distance reduces the frequency of social interactions and implicitly the flows of support between generations (see for example Rossi and Rossi, 1990: 416-422). However, recent understandings concerning transnationalism as a concept - taken from the everyday practices of individuals - show that "migrants establish social fields that cross geographic, 
cultural and political borders" (Glick-Schiller et al., 1992: ix). Transnationalism from below emphasises the subjective meanings and the practices developed by migrants in relation to and towards what they have left in the country of origin. We can mention here aspects like the symbolic notion of home (see Olwig, 2002), the transnational domestic sphere (Gardner and Grillo, 2002), and transnational families (see Baldassar et al., 2007). This perspective concerns not only individuals who emigrate, but also considers the significant others that live in the homeland and long-distance connections:

[...] those family members who stay behind or stay put (as it were) in their place of birth or ancestral homeland also become part of social relationships stretched across time and place, even though they might never actually relocate or move at all. (Baldassar and Merla, 2014: 6)

Current family studies tackling the issue of increased geographic distance between family members provide empirical evidence stressing out that mobility is a common feature among contemporary kinship groups and that "members of families retain their sense of collectivity and kinship in spite of being spread across multiple nations" (Baldasar et al., 2007: 13). Multi-national kin groups or family members living separated by increased geographic distance (i.e. transnational families) are defined as "families that live some or most of the time separated from each other, yet hold together and create something that can be seen as a feeling of collective welfare and unity, namely familyhood, even across national borders" (Bryceson and Vuorela, 2002: 3). Transnational families display similarities with families whose members live in geographic proximity, at least on two grounds including diversity and types of support. On the one hand "a wide variety of socioeconomic, educational, cultural, ethnic and religious backgrounds, and with extremely different levels of social, economic, cultural and symbolic capital (Bourdieu, 1986), in both their home and host societies" (Baldassar and Merla, 2014: 9) is observed. On the other hand, transnational families acquire similar social interactions and support practices as families living in geographical proximity (Baldassar et al., 2007; Wilding, 2006).

\section{Doing family across national borders}

\section{Typologies of transnational visits}

Based on theoretical frameworks concerning transnational families, we bring into discussion two essential concepts, namely transnational caregiving and care circulation. The term transnational caregiving is used with reference to the 
exchange of care and support across distance and national borders (Baldassar et al., 2007). Care circulation is defined as "the reciprocal, multidirectional and asymmetrical exchange of care that fluctuates over the life course within transnational family networks subject to the political, economic, cultural and social contexts of both sending and receiving societies" (Baldassar and Merla, 2014: 25).

Transnational care is a complex process that also encompasses visiting, both migrant visits (made by migrants to homeland) and parental visits (made by parents to their migrant adult children). In this respect, Baldassar et al. (2007), described five types of visits in their understanding of the importance of visits in the transnational caregiving process. The first type of the visits explained is routine visits. This kind of visit is most prevalent for people who can visit periodically in order to manage employment, professional or investment duties. Most often, migrants who can afford to engage in routine visits use these opportunities to also reach out to the family. There is no specific motivation associated to routine visits other than visiting and being with the family.

Crisis visits are more specific than routine visits and they have special motivations. They involve the need to care for the distant kin, usually through the provision of hands on care, or they are related to an urgent matter such as serious illness, difficulty after birth, divorce. Attending key celebrations and anniversaries, and participating in rites of passage (births, deaths, and marriages) are duty and ritual visits. This type of visit is expected and anticipated and is most often perceived as an obligation to attend, sometimes implying ambivalence. Of course, some visitors may be very keen to attend life-cycle events, including weddings and special anniversaries, and do not feel constrained to participate. Special visits or purpose visits have precise purposes, particularly the first birth, transition times when elderly parents change their living arrangements, or the final stages of a terminal illness. An important reason behind special visits is to relive the migrant's homesickness or to alleviate the anguish of being away from parents / children and grandchildren. Finally, there are tourist visits characterized by short visits to kin focused on travelling and visiting tourist sites. Tourist visits have their importance and can result in an expanding of the transnational networks of caregiving, involving a consolidation of relationships between migrants and kin (Baldassar et al., 2007).

\section{Dealing with emotions and feeling the presence of the longed ones}

Due to the geographical distance and timespan, transnational families are experiencing emotional situations such as the absence of loved ones and longing to be together. In order to strengthen their relationships of reciprocity and caregiving, migrants and their parents make use of varied types and 
degrees of co-presence. According to Baldassar (2008) there are four main ways of co-presence: virtual co-presence, co-presence by proxy, physical copresence and imagined co-presence. Additionally, Madianou (2016) discusses about a new form of information and communications technology (ICT) mediated contact, namely ambient co-presence.

The co-presence topic can be discussed extensively if we consider the substantial ethnographic work of Baldassar et al. (2007), Madianou and Miller (2012), Madianou (2016) and others. However, for this research we limit our inquiry in providing some information, mainly describing how these various types of co-presence are used in transnational families. Considering the reduced cost of communication technologies in the last years and the considerable advances in the field, virtual co-presence is prevailing. Virtual forms of copresence are represented most often through the sense of hearing, either directly in verbal exchanges via landline, mobile phone or Voice over Internet Protocol, or indirectly in written communication forms, such as emails, SMS or other services for instant messaging (Baldassar, 2008; Madianou and Miller, 2012). Being the most extensive form of transnational communication, virtual copresence is usually described as keeping in touch and staying in contact (Baldassar, 2008). Another important aspect of transnational contact is related to the access to stable, affordable and appropriate technologies, and as well having the capacity in terms of health, skills and knowledge to handle various communication technologies. For example, the usage of technologies is limited among parents suffering from mental illnesses such as dementia which is strongly associated with ageing (Baldassar, 2008).

Co-presence by proxy is represented by special transnational objects such as photos, cards, gifts, which hold a very strong emotional dimension. A more valued type of co-presence among transnational families, but not as easily achieved as virtual co-presence, is the form of physical co-presence. Baldassar (2008) describes physical co-presence as a need felt by migrants and parents to see with their own eyes and to confirm for themselves that they are healthy and in good physical and mental shape. Baldassar et al. (2007), confirm in their studies that access to new communication technologies increases the obligation and need for virtual co-presence along with advances in travel technologies which provide transnational families with opportunities to be more physically co-present and to develop new forms of co-presence.

\section{Typologies of care and early empirical evidences}

In terms of care, early studies distinguish between various intergenerational forms of support: economic support, accommodation, personal care, practical 
support, child care, and emotional or moral support (Finch, 1989). When spatial proximity becomes an issue, Litwak and Kulis's (1987: 659) schema for measuring the strength of kin differentiates between three indicators: (a) telephone contacts frequency, (b) frequency of services that do not require faceto-face contact (e.g., advice and emotional succour), and (c) frequency of services that require only limited face-to-face contact (e.g., help during acute illness, death of spouse, birth, and marriage). Based on Baldassar et al.'s (2007) multidimensional classification of proximate and virtual caring practices, Kilkey and Merla (2014) develop a new schema of the four types of care provision. The authors differentiate between direct provision with physical co-presence, direct provision at a distance, coordination of support, and delegation of support (Kilkey and Merla, 2014: 213).

Results emphasized by the ethnographic research of Baldassar et al. (2007) show that the quantity and the regularity of visits from parents to migrant children are important for the so-called staying in-touch and for copresence care. In their group sample, on average, parents visit the migrant children once every three to four years. Also, migrant adult children tend to visit more than their parents. This aspect may indicate that, after all, the obligation to maintain the connections and ties with those left at home is felt more by those leaving the homeland. This pressure to visit (as it may be perceived) becomes even more present with the increased advances in travel technologies. Moreover, the fact that aging parents become unavailable to travel long distances strengthen the previous idea. Nevertheless, visits can have an important role in maintaining and challenging transnational family relations, including the acceptance of changes and the fulfilling of familyhood (Baldassar et al., 2007).

As transnationality considers not only the migrants but also the significant others in the homeland, a recent study about Romanian transnational families highlight that elderly parents are also active participants in maintaining family bonds across large geographic distances (Hărăguș et al., 2018). Even though the practical support offered by parents to their children has mostly lost its daily character in the transnational setting, various forms of succour continue to be present both in physical co-presence during parents' visits and from a distance in the home country (Hărăguș et al., 2018). Other recent research using survey data identifies several clusters of family relationships types between aging parents and migrant adult children. A first typology of transnational solidarity distinguishes three sub-groups of family practices, namely harmonious, detached and obligatory (Karpinska and Dykstra, 2018). 
The first classification highlights high likelihood for two-way intergenerational emotional assistance and upward material support, the third relies more on increased contact, while the detached type implies low support and contact probabilities and a high likelihood of weak filial obligations (Karpinska and Dykstra, 2018). Another typology of family relationship among non-co-resident children and their parents identifies four different solidarity clusters: full solidarity, advice-oriented solidarity, material-oriented solidarity and autonomy (Baykara-Krumme and Fokkema, 2018). Against the authors' hypothesis, full and material-oriented solidarity are considered present forms of solidarity among transnational dyads (Baykara-Krumme and Fokkema, 2018).

\section{Research hypotheses}

We build our hypothesis following Morgan's (2011) concepts of doing family and family practices while addressing the issue of transnational relationships across generations. Increased opportunities for traveling long distances and contact via technology has significantly changed the interactions between transnational family members (Baldassar et al., 2007; Baldassar, 2008; Madianou and Miller, 2012; Madianou, 2016). In line with our cited literature, we assume that migrant adult children are more mobile regarding transnational visits as compared to their elderly parents (1). Considering ICT contact, most parents are regularly in touch with the emigrated offspring, and technology represents a great means for emotional assistance (2). As described earlier in this section, financial support and practical care are also part of transnational family life. Subject of variations in terms of the types of hand-on support, we expect both elderly parents and adult children to be providers and beneficiary of various kinds of intergenerational assistance (3). In line with Finch's (1989) results, we expect that upward material support (namely remittances in cash or in kind towards senior parents living in homeland) to be more frequent than material support from parents towards emigrated adult children (4). The felling of copresence with the longed one, both physical and virtual, has a great importance for keeping alive and strengthening family relationships across distance (Baldassar, 2008). Therefore, we assume that the presence of contact between parents and their adult children living abroad is linked with other forms of intergenerational exchanges (5). The last hypothesis aims to capture the link between all these forms of support and social interactions. Regarding the overall picture of the forms of intergenerational relationships across distance, we expect to find several clusters of family-like practices (6). 


\section{Data and methodology}

Our data is the result of a nation-wide survey among ageing parents (60 years of age and over) living in Romania and who have at least one adult child living abroad. The survey is part of the research project entitled Intergenerational solidarity in the context of work migration abroad. The situation of the elderly left at home (SolFam). For sampling and data gathering we used a stratified sampling technique. In the selection procedure we started with Romania's eight development regions. From each development region two counties (administrative areas) were randomly selected. The subsequent stratification criterion was the settlement type, namely large urban areas (over 50,000 inhabitants), small urban areas (under 50,000 inhabitants) and rural settlements. Within each stratum mentioned above we have randomly selected towns and villages. The respondents' distribution in these three community types reflects, at the level of each region, the national distribution of persons aged 60 and over. Respondents were identified by research operators through screening, by means of local informers: public and private institutions that maintain contact with potential respondents (for example: city halls, social service departments, day-care centres for elderly people, organisations that provide care services etc.) or by using the snowball technique, through recommendations received from already-interviewed individuals. The data was collected between April and December 2016. The final sample composition is presented in Table 1.

Table 1.

\section{Descriptive statistics of the sample composition}

\begin{tabular}{|c|c|c|}
\hline Number of households and interviews & 1506 & - \\
\hline Long-term emigrants & 2072 & $98 \%$ \\
\hline Sumber or emigrated adul seal emigrants & 37 & $2 \%$ \\
\hline chilaren Total & 2109 & $100 \%$ \\
\hline $\begin{array}{l}\text { Number of emigrated adult children without any information } \\
\text { about their relationships with the parent }\end{array}$ & 79 & $4 \%$ \\
\hline Total & 2188 & $100 \%$ \\
\hline
\end{tabular}

Data source: SolFam, 2017. Authors' calculation 
Face-to-face interviews were conducted during the field research and the data was collected using the pen and paper technique. A large part of the questionnaire focuses on the parent-migrant adult children relationship and their migration arrangements. The questions were addressed separately for each adult child living abroad. This section comprises information about the destination country, the year of emigration, the child's living arrangements and parent's thoughts about returning migration intentions. Also, we used a wide set of measures for the associative solidarity, emotional solidarity and functional solidarity. Namely we considered the frequency of technologically mediated contacts (ordinal scale), the type (nominal scale) and frequency of visits (numeric scale) both in the destination country and homeland, and of upward intergenerational support (receiving support from the children), as well of the downward intergenerational support (providing support to children). The questions asked were related to the provision and benefiting of practical support in the household, personal care (only received), help in taking care of grandchildren (only provided), practical support from the distance (only provided), financial help and material help in kind. Because practical support, both provided and received, is dependent upon the provider's and the beneficiary's simultaneous physical presence in one of the two households, it linked with the visiting time. Practical support provided from distance, which is possible without the reciprocal physical presence of the dyads, offers information about the situation in which parents help their adult children with various administrative tasks (regarding the household in Romania, the construction site for a new house or building, a business endeavour in Romania or paying taxes for the child living abroad). All these items are yes or no variables. Also, parents were asked if they take care of the underage grandchildren who remained in Romania (ordinal scale). Financial help refers to regular or occasional money transfers, gifts or loans. With regards to the material support we distinguished between groceries or household items and properties or goods of a substantial value, such as houses, land parcels, cars, etc. Because the act of migrating was considered a turning point, we wanted to identify potential differences between the period prior to and after the departure (the last 12 months if the child emigrated for more than one year or since he or she left, if less than one year), therefore for each type of support we addressed up to date and retrospective questions.

Our analytical approach consists of two steps. In the first part we will present descriptive results concerning various types of family practices across generations and national borders. Data was collected from all children-parent dyads, excluding the cases where there was no information about emigrated adult child. The second step provides the result of Latent Class analyses of 
intergenerational family practices in transnational context. LC analysis is a nonlinear model specific for categorical data which assumes the probabilistic relationships between latent constructs and the measures used in each statistical model (see Agresti, 2002; Magidson and Vermunt, 2001, 2004; Lazarsfeld and Henry, 1968). Therefore, our aim is to identify heterogeneous subgroups that classify various intergenerational family dyad relationships into homogenous subcategories or latent classes. For this purpose, we used the poLCA function in R (Linzer and Lewis, 2011, 2013). Model testing was preceded by two methodological steps considering the independence condition of the variables and the uniformity of measurement scales. Firstly, in order to achieve the independence condition, we randomly selected one emigrated adult child from each household (one child of each parent we interviewed). Secondly, due to the diversity of the measurement scales of the variables mentioned above, we recoded them into dichotomous variables $(\mathrm{No}=1$, Yes $=2)$. For the visits' frequency, ' 0 ' stands for no visits and ' 1 ' for at list one visit. Considering the frequency of ICT contact, ' 1 ' equals weekly and more frequent discussions and ' 0 ' means less than weekly ICT contact. We ran two different models which will be presented later. To achieve more accurate results, each model was run 10 times in order to locate the parameter values that globally maximize the log-likelihood function (McLachlan and Krishnan, 1997). The first model includes ICT contact, emotional assistance, remittances in kind, remittances in cash, money support from parents, support in kind from parents, downward succour from a distance and visits. For the other model we replaced the variables measuring visits with practical support during visits.

\section{Results}

\section{Visits, virtual contact and emotional support}

Non-migrant kin visiting the homeland and parents' visiting the country of destination are common practices among Romanian transnational families. In the past years, traveling expenses have been reduced and the transportation services between countries have become more and more diverse and accessible. Results presented in Figure 1.1 show that more than $70 \%$ of emigrated adult children visited their elderly parents at least once in the past 12 months or so from the interview date. On the other hand, ageing parents are less mobile, but still there is a significant share of elderlies traveling abroad. 


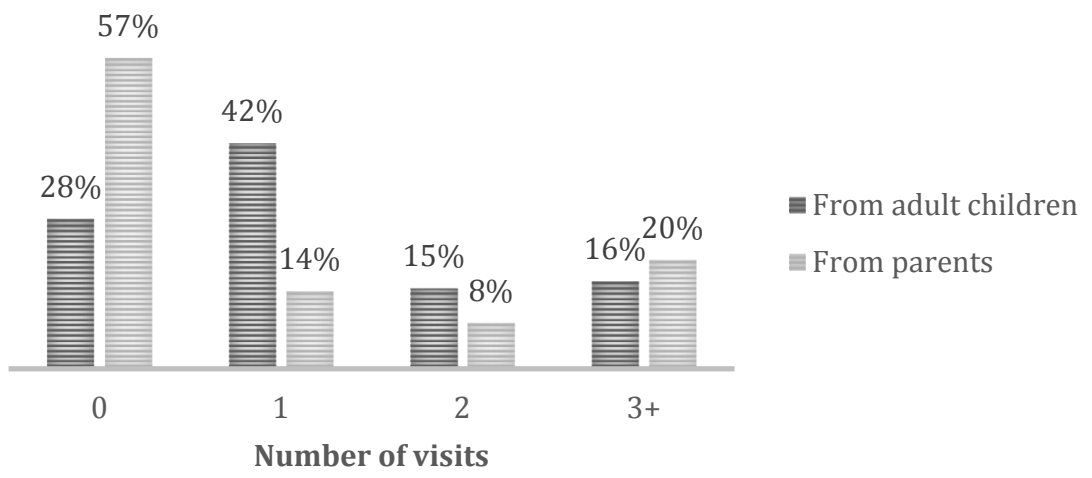

Figure 1.1. Number of visits across borders

Data source: SolFam, 2017. Authors' design

This is in line with our first hypothesis, namely that the younger generation is more frequently engaging in long distance travels in order to visit their parents back home (H1). These return visits have a major role in maintaining kinship bonds across time and distance (Baldassar, 2001). Apart from the urgency of the visits and its major role for keeping the emotional closeness with the parent, migrant visits are more frequent due to the increased access to travel information and financial resources to pay for the travel expenses.

Nevertheless, some of these transnational parents are also significantly involved in such family practices. The data shows that they spend more time in the receiving country than adult children during their return visits in the homeland (Figure 1.2). This can be an indicator of the visiting motivations and the types of support provided in physical co-presence. Based on an adaptation of Baldassar et al.'s (2007) typology of transnational visits, the most common category of visits in our data sample are routine visits (Figure 1.3). Besides this, parents usually travel in order to fulfil their perceived parental roles and grandparent responsibilities. Adult children also return for short periods in order to attend family reunions or family rituals such as weddings, funerals and other. Another reason for travelling is related to times of crisis, mostly among emigrants. Crisis situations are usually related to medical problems of the parent or to the death of a close family member. 


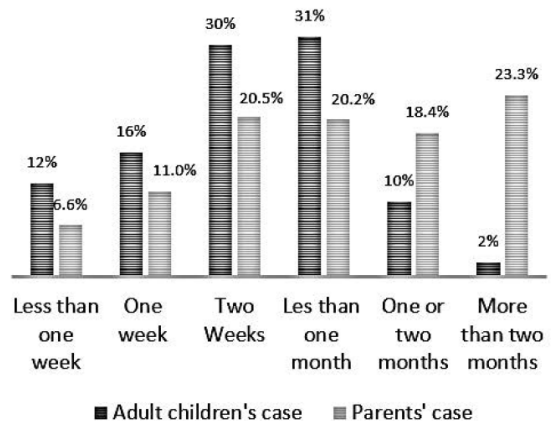

Figure 1.2. Visit duration Data source: SolFam, 2017. Authors' design

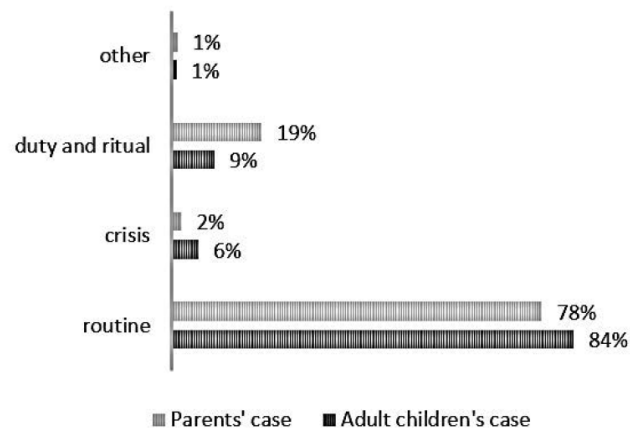

Figure 1.3. Visit types

Data source: SolFam, 2017. Authors' design

Other means used by transnational family members in order to stay in touch with each other are information and communication technology. ICT contact became the most widespread method of communication across distance and due to new technological advances, it also decreases the costs of maintaining regular contact between family members. Figure 2 highlights the importance of having access to communication technologies. Most of the parents are in contact with their emigrated children at least once per week. A significant share of transnational family members uses these means of contact daily. Half of our respondents declared that they spend between 10- and 30-minutes having conversations with their child living abroad. The access to a Polymedia environment (Madianou and Miller, 2012) increases the opportunities to be in touch among separated family members. Such virtual interactions create the feeling of co-presence which decreases the longing for the missing child (Baldassar, 2008). The regularity of such interactions is in line with early studies showing that ICT-mediated contact is a form of practices that "possesses a sense of the everyday, a sense of the regular and a sense of fluidity" (Nedelcu and Wyss, 2016: 205).

Virtual contact is also perceived as having a powerful sense of emotional support. Figure 3 shows increased occurrence of intergenerational emotional assistance among transnational family members. One possible reason for such a widespread family practice is linked to the limits imposed by living at a distance. Confirming our second hypothesis, results show that there is an increasing need for emotional support among transnational family members and technology is the most important mediator. We can assume that emotional assistance while engaging in virtual contact is the most accessible form of 
intergenerational support in terms of means. Also, this polymedia environment enables people to control what they are virtually displaying while using communication technologies (Madianou and Miller, 2012). Our results show that conversation via landline technology is the most preferred sensitive topics. By doing so, both parents and adult children avoid displaying their corporal or physical manifestations of their negative emotions. Early qualitative research on Romanian transnational family members, stress that financial reasons and skills are the main factors of choosing the right means for communication across distance (Ducu, 2016).

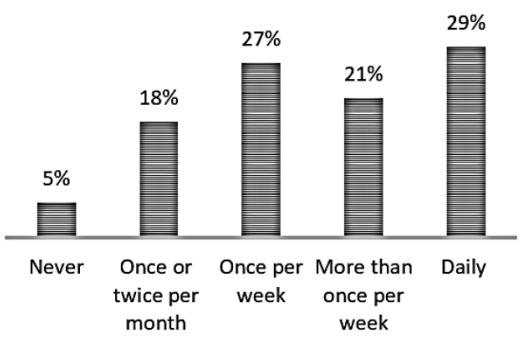

Figure 2. Technological mediated contact Data source: SolFam, 2017. Authors 'design

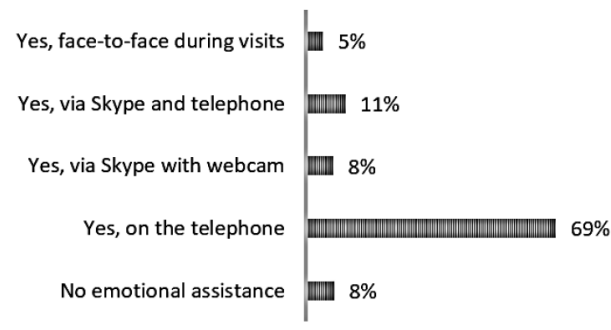

Figure 3. Emotional assistance Data source: SolFam, 2017. Authors' design

\section{Practical support during visits}

Providing or receiving familial support may occur in both physical copresence and from a distance (Baldassar et al., 2007; Litwak and Kulis, 1987; Kilkey and Merla, 2014). Practical or time-consuming assistance in co-presence is directly related to the type and duration of the visits. Figure 4 shows that among the dyads, namely adult children and ageing parents, the most common type of upward practical help involves household chores. During visits, an increased share of adult children also provides other types of support, such as giving professional advice or offering medical related assistance. Compared to these forms of intergenerational succour, only a small number of emigrated children are engaged in personal care for their elderly parents. Of course, offering and receiving personal assistance is subject to an increased physical dependence of the parent and a precondition of constant proximity between the beneficiary and the provider. Consequently, our descriptive statistics are also influenced by the share of parents who are not able to meet their daily needs independently. 
Only a reduced number of respondents in our sample declared that they need regular personal assistance (data available upon request). Among other motives, the parents' medical urgent problems are generally a trigger for return visits (Baldassar et al., 2007). Therefore, the relatively reduced frequency of crisis visits from emigrated offspring is also an indicator for the lack of upward personal assistance.

Regarding the help from elderly parents during their visit abroad, doing household chores and grandchildren rearing are the two forms of downward support that we measured (Figure 5). As the literature highlights, these types of intergenerational succour are also very common among transnational mobile grandparents (Treas and Mazumdar, 2004). Our results reinforce the increased commitment among older generation members - also known as the Zero Generation (Nedelcu, 2007, 2009) - to provide intergenerational support even if this involves traveling long distances. When grandchildren are born and if the elderly are healthy, the grandparents' visits are mostly triggered by their willingness and/or by the need of the adult children to receive support.

Considering both directions flows of intergenerational practical support, our empirical evidence suggests that hands-on care continues to be a part of the family life even if it involves traveling long distances. Arguably, this is a very good example of how keeping the family together is not limited to spatial proximity. Finally, we also confirm our hypothesis regarding the multidirectional feature of practical support among transnational families (H3).

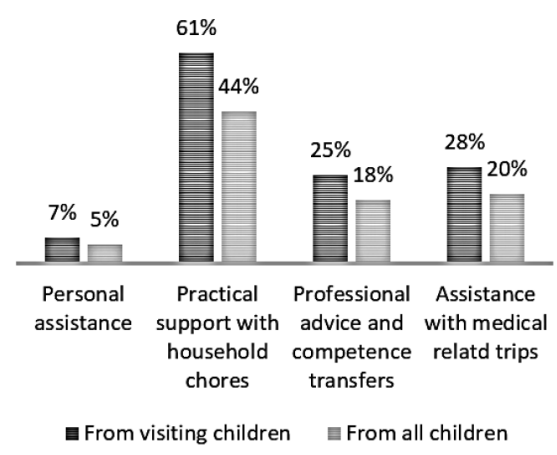

Figure 4. Provision of upward support with physical co-presence Data source: SolFam, 2017. Authors' design

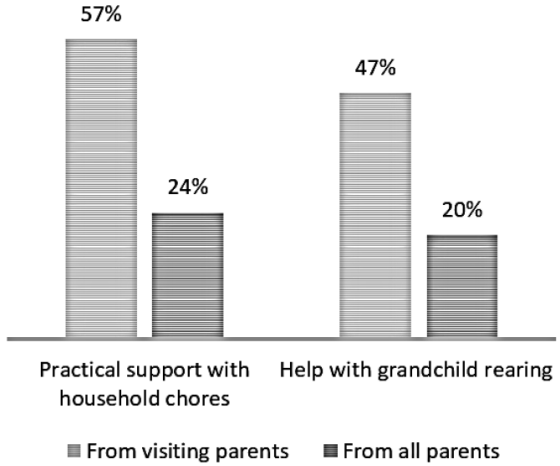

Figure 5. Provision of downward support with physical co-presence

Data source: SolFam, 2017. Authors' design 


\section{Practical and material support from a distance}

Considering intergenerational practical support from a distance, our data gives information only about time-consuming activities in which aging parents are engaged. We distinguish here between administrative practical support and grandchild care. For administrative support we considered the provision of at least one of the following types of help: keeping the child's own house in Romania in good condition, supervision of the construction site of a new house or building, business endeavours in Romania on behalf of the adult child or paying taxes for the child living abroad. Among parents who are left in charge with various responsibilities by their mobile offspring, Figure 6 highlights that more than $70 \%$ of the emigrated adult children who left their underage children in Romania receive childcare support from their parents. One quarter of the transnational ageing parents are also engaged in various management duties on behalf of their emigrated offspring. Unfortunately, we do not have precise data in order to distinguish between adult children who require administrative practical support and those who do not.

We can argue that caring from a distance is a family practice that holds the intergenerational family together across distance. It can be also a form of family display (Finch 2007) showing that this is a family that works (Morgan, 2011: 86). Moreover, we can suggest that the engagement in such types of familylike activities has the potential for non-migrant parents to experience a sentiment of co-presence by proxy (Baldassar, 2008). Providing intergenerational support from a distance by caring for grandchildren or managing the construction/ renovation of the house building can trigger both bodily feelings and emotions for the longed ones.

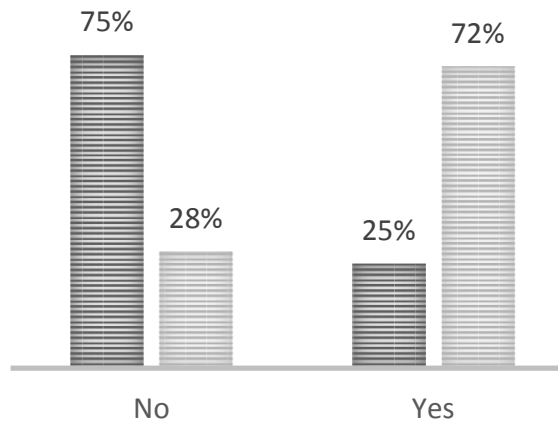

E Administrative practical support

Practical support with grandchildren rearing

Figure 6. Provision of downward practical support from a distance Data source: SolFam, 2017. Authors' design 
Material support can consist both in money transfers and in the provision of goods or commodities. Such familial support does not necessarily imply spatial proximity; money can be sent for example via online banking and goods can be transported by a third party. Figure 7.1 stresses out the dissimilarities between generations when it comes to transnational money transfer. As expected, it is more common among emigrants to send remittances in cash to their parents, rather than receiving financial support from the homeland (see also Finch and Mason, 1993; Hărăguș and Telegdi-Csetri, 2018). The empirical findings confirm our research hypothesis (H4). Regarding remittances towards elderly parents, our data shows that half of the emigrated adult children provided upward financial support while the other half were not. Arguably, the lack of transfers of remittances does not imply broken family bonds or disrupted connections. Some of the children provide financial support only to their own nuclear family, while the commitment towards parents is expressed by other means. Also, financial assistance like other types of familial support is conditioned by the structures of needs and opportunities of both parents and adult children (Szydlik, 2016). Emigrated children may not have the proper opportunities to provide remittances. Likewise, parents who are financially well-off will not require intergenerational support in cash from their offspring.

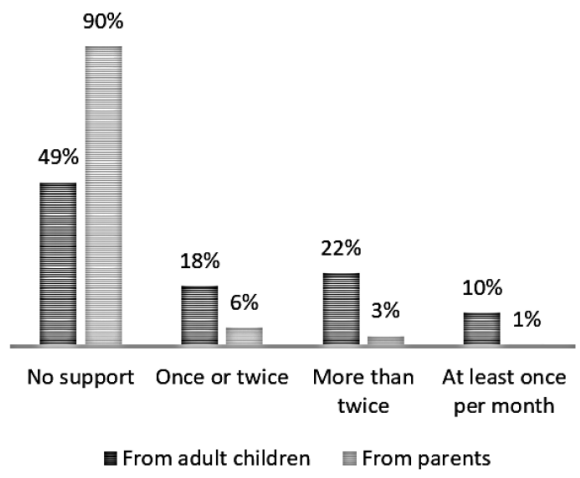

Figure 7.1. Provision of support in cash Data source: SolFam, 2017. Authors' design

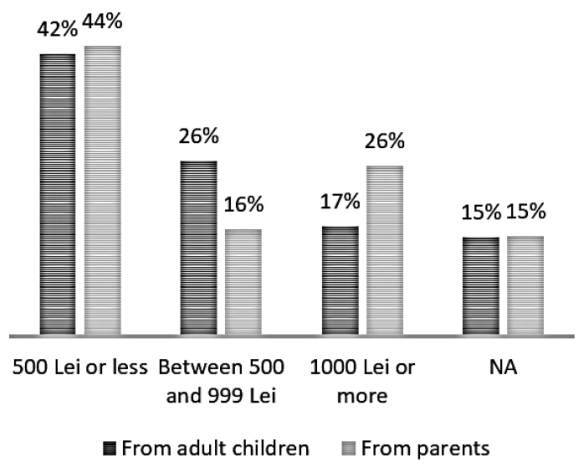

Figure 7.2. Amount of money transfers Data source: SolFam, 2017. Authors' design

The frequency of intergenerational remittances in cash is subject to variations between those emigrants who are engaged in upward money transfers. Figure 7.1 shows that it is more common among our sample of ageing parents to receive money from abroad several times in a year, but not every 
month. Figure 7.2 shows relatively small amounts of remittances in cash that the parent declared to have received from the emigrated adult child. However, we must pay more attention to this result. On the one hand, the total amount of remittances for each household can increase when more children are working abroad. Also, other adult children, not necessarily those who emigrated, can be a source of financial help. On the other hand, most elderly people are beneficiary of public pensions and remittances are a supplement in order to make the basic ends meet.

As mentioned before, exchanging goods or commodities is not limited to physical co-presence. We also addressed the fact that means of transportation become increasingly varied and accessible. Figure 8 highlights a slight increase in the share of parents' beneficiary of remittances in kind compared to the number of parents who provide downward support in kind.

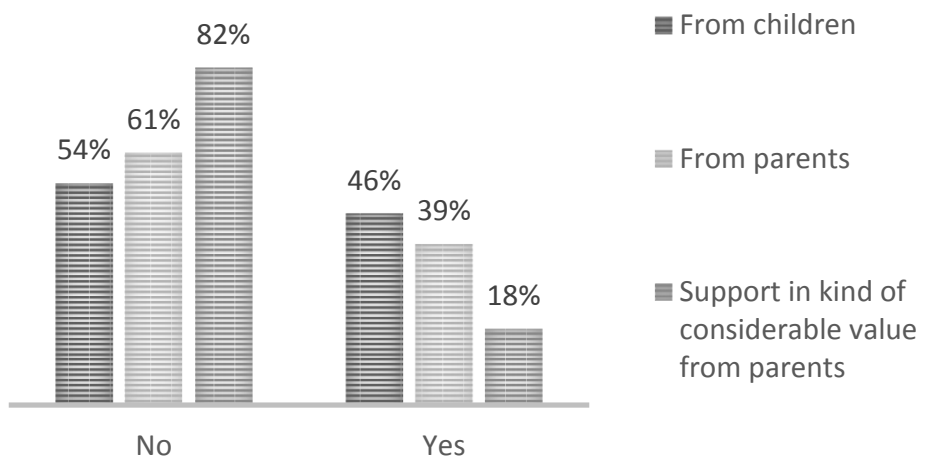

Figure 8. Provision of support in kind

Data source: SolFam, 2017. Authors' design

However, the difference between the two generations regarding the provision of support in kind is not big enough to agree with our expectations (H4). It was made clear that emigrated children are the most frequent providers of support in cash. We cannot say the same thing about support in kind. A potential explanation for relatively increased lack of support in kind among transnational families is also the globalized consumption market specific for Romania. In line with early empirical findings (see for example Baldassar et al., 2007; Baldassar, 2008), we can assume that support in kind is rather a practice 
of exchanging gifts on special occasions such as transnational visits, family rituals attendance and other family-like events. If support in kind can be translated in gift exchange practices, this family practice has a great potential for triggering the feeling of co-presence (Baldassar, 2008). Different transnational objects or gifts are proxies for creating and recreating memories about the children who live across the world.

\section{Links between intergenerational family practices}

As we stated earlier, when considering traveling and visiting across borders, ageing parents are significantly less mobile than their emigrated adult children. However, during visits, parents and adult children are enabled to provide direct practical support. Figure 9.1 shows the relationship between visits and practical support in physical co-presence. Both dyads usually provide timeconsuming help during visits, but there are situations when visits do not necessary imply hands-on support. We can assume that in this case, the lack of practical support during visits is related to the structures of needs and opportunities of the kin members involved. Likewise, we can discuss about a change in cultural values. Emigrants can reshape their own life style accordingly to the 'new' culture of the receiving community. Therefore, practical help from their elderly parents may no longer be needed.

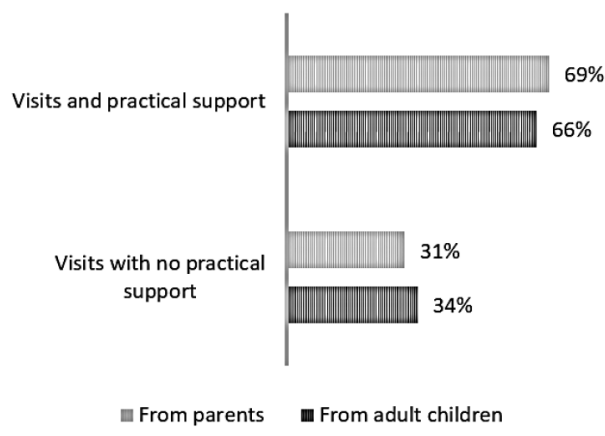

Figure 9.1. Visits and practical support in physical co-presence

Data source: SolFam, 2017. Authors' design

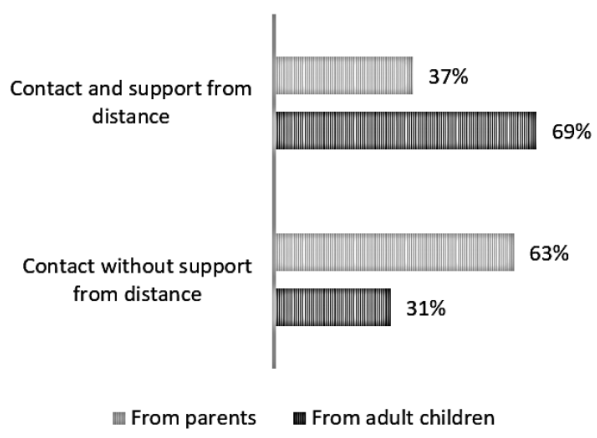

Figure 9.2. ICT Contact and support from distance

Data source: SolFam, 2017. Authors' design

Similar results among emigrated children are observed in Figure 9.2 on the link between ICT contact and practical support from a distance. Remit practices are highly related with being in touch transnationally. On the other 
hand, the percentage of parents who maintain contact with their mobile children without provision of practical or material support is higher than those who would also provide help from a distance. These results stress the fact that staying in touch across distance is essential in order to exchange other forms of intergenerational support. Visits and telephone calls are not just simple family practices. Due to the increased geographical distance the emotional and affective meaning of such interactions is even more intense. Therefore, some transnational families are 'holding together' based on the feeling of co-presence without being involved in other forms of actual support. Based on these results we can only partially agree with our hypothesis about the link between transnational contact and transfers of support (H5).

The final part of this section deals with the construction of homogenous parent-child dyad subgroups based on various intergenerational family practices in transnational settings. Our aim is to further explore the link between all the family care practices analysed so far. We considered the optimal number of clusters based on the lowest values of BIC and AIC. These information criteria are functions of the number of parameters, sample size, and log likelihood and are the most widely applied criteria for model selection (Magidson and Vermunt, 2004). Because practical support in physical co-presence requires visiting, these two variables are dependent on each other. For this reason, we modelled two separate sets of LC analyses. The first LC model includes ICT contact, visits, emotional assistance, remittances in kind, remittances in cash, money support from parents, support in kind from parents, downward succour from a distance. Based on the model fit information, the optimal number of clusters is equal to 4 . The second CL model includes the same variables, excepting visits measures that were replaced with ascendant and downward practical support during visits. In this case the optimal model involves three different subgroups.

Table 2 shows the class membership probabilities of each of the items measuring family practices with regards to ICT contact, face-to-face contact and emotional, material or practical support. Highest probabilities for each category of the items are marked with bold in order to highlight cluster membership. These sub-groups have different population shares which suggests another essential insight regarding family relationships across generations in a transnational context. The less common is Cluster 1 showing the lack of involvement or no strong ties. Considering the classification of Karpinska and Dykstra (2018), these subgroups could be labelled as detached solidarity. The second cluster exhibits increased ICT contact, emotional support, high involvement of adult children and downward reciprocity from a distance. Here, emigrants have larger probabilities to be more mobile than their parents and are a great source of remittances. As a 
form of reciprocity from parents, we observed weekly contact with their offspring living abroad and providing time consuming help in the homeland, therefore we could consider this subgroup as harmonious solidarity relationships. Family practices concerning emotional support emerge another distinct cluster which stresses out the intense affectivity among transnational families. This group of family practices has the highest population share followed immediately by harmonious family practices. The not so widespread subgroups show the highest probabilities for visits and material support from parents. We can assume the increased dependency among emigrants for theirs parents help and the increased parental involvement in transnational setting.

Table 2.

Results of LC analysis with variables measuring transnational visits. Conditional item probabilities by variable response and class

\begin{tabular}{lll|ll|ll|ll} 
& \multicolumn{2}{l}{ Cluster 1 } & \multicolumn{2}{l|}{ Cluster 2 } & \multicolumn{2}{l|}{ Cluster 3 } & \multicolumn{2}{l}{ Cluster 4 } \\
\hline & Yes & No & Yes & No & Yes & No & Yes & No \\
\hline ICT Contact & 0.011 & $\mathbf{0 . 9 9 0}$ & $\mathbf{0 . 6 3 8}$ & 0.363 & 0.529 & 0.471 & 0.626 & 0.374 \\
Visits from children & 0.372 & $\mathbf{0 . 6 2 9}$ & $\mathbf{0 . 9 0 2}$ & 0.098 & 0.693 & 0.307 & 0.789 & 0.211 \\
Visits from parents & 0.117 & $\mathbf{0 . 8 8 3}$ & 0.429 & 0.571 & 0.391 & 0.609 & $\mathbf{0 . 6 6 6}$ & 0.334 \\
Emotional assistance & 0.566 & $\mathbf{0 . 4 3 4}$ & $\mathbf{0 . 9 9 1}$ & 0.009 & $\mathbf{0 . 9 7 0}$ & 0.030 & $\mathbf{0 . 9 3 6}$ & 0.064 \\
$\begin{array}{l}\text { Remittances in cash } \\
\text { from children }\end{array}$ & 0.066 & $\mathbf{0 . 9 3 4}$ & $\mathbf{0 . 9 2 5}$ & 0.075 & 0.459 & 0.541 & 0.156 & 0.844 \\
$\begin{array}{l}\text { Remittances in kind } \\
\text { from children }\end{array}$ & 0.149 & $\mathbf{0 . 8 5 1}$ & $\mathbf{0 . 9 0 7}$ & 0.093 & 0.163 & 0.837 & 0.663 & 0.337 \\
$\begin{array}{l}\text { Support in cash from } \\
\text { parents }\end{array}$ & 0.065 & 0.935 & 0.029 & $\mathbf{0 . 9 7 1}$ & 0.073 & 0.927 & $\mathbf{0 . 2 8 4}$ & 0.716 \\
$\begin{array}{l}\text { Support in kind from } \\
\text { parents }\end{array}$ & 0.023 & $\mathbf{0 . 9 7 7}$ & 0.535 & 0.465 & 0.128 & 0.873 & $\mathbf{0 . 8 0 6}$ & 0.194 \\
$\begin{array}{l}\text { Downward support } \\
\text { from distance }\end{array}$ & 0.189 & $\mathbf{0 . 8 1 1}$ & $\mathbf{0 . 4 4 7}$ & 0.553 & 0.224 & 0.776 & 0.342 & 0.658 \\
\hline $\begin{array}{l}\text { Estimated class } \\
\text { population shares }\end{array}$ & $12 \%$ & & $30 \%$ & & $41 \%$ & & $17 \%$ & \\
\hline
\end{tabular}

Data source: SolFam, 2017. Authors' calculation

Instead of visits, the second LC model includes intergenerational handson practical support offered during visits in homeland or abroad. The three clusters' composition and item probabilities are presented in Table 3. The first latent dimension comprises rather the lack of transnational family practices. 
However, this time the composition of the cluster is not as straightforward as the one from Table 2. The second cluster relates to material support provided by parents while the third, which is the most common, emphasizes the occurrence of all the other family practices. Cluster 2 in Table 3 has a similar manifest composition with the forth cluster in Table 2, that is increased parental involvement. Moreover, it shows high probabilities of no remittances and lack of practical support in co-presence from emigrated children. This is in accordance with other empirical findings which highlight that material support, usually consisting in money is not transferred from both generations at the same moments in time. Cluster 3 in Table 3 highlights the strong link between ICT and physical contacts, emotional support and remittances from the emigrant adult child towards her or his elderly parent. These two typologies of transnational care presented in Table 2 and Table 3 give enough evidence to confirm our research hypothesis (H6). It was showed that we cannot talk in terms of a dichotomy, transnational families that work and transnational families that do not work. The web of transnational care practices and intergenerational relationships across distance is more complex, showing diversity and fluidity in terms of actions and meanings.

Table 3.

Results of LA analysis with variables measuring practical support during visits. Conditional item probabilities by variable response and class

\begin{tabular}{lll|ll|ll} 
& \multicolumn{2}{l|l|l|l|l}{ Cluster1 } & \multicolumn{2}{l|}{ Cluster 2 } & \multicolumn{2}{l}{ luster 3 } \\
\hline & Yes & No & Yes & No & Yes & No \\
\hline ICT Contact & 0.483 & $\mathbf{0 . 5 1 7}$ & 0.613 & 0.387 & $\mathbf{0 . 7 2 0}$ & 0.280 \\
Emotional assistance & 0.937 & 0.063 & 0.936 & $\mathbf{0 . 0 6 4}$ & $\mathbf{0 . 9 8 2}$ & 0.018 \\
Remittances in cash from children & 0.400 & 0.600 & 0.080 & $\mathbf{0 . 9 2 0}$ & $\mathbf{0 . 8 8 9}$ & 0.111 \\
Remittances in kind from children & 0.236 & $\mathbf{0 . 7 6 4}$ & 0.672 & 0.328 & $\mathbf{0 . 8 0 4}$ & 0.196 \\
$\begin{array}{l}\text { Support in cash from parents } \\
\text { Support in kind from parents }\end{array}$ & 0.158 & 0.842 & $\mathbf{0 . 2 9 0}$ & 0.710 & 0.014 & $\mathbf{0 . 9 8 6}$ \\
$\begin{array}{l}\text { Downward practical support from } \\
\text { distance }\end{array}$ & 0.064 & $\mathbf{0 . 9 3 6}$ & $\mathbf{1 . 0 0 0}$ & 0.000 & 0.555 & 0.445 \\
$\begin{array}{l}\text { Upward practical support during } \\
\text { children's visits }\end{array}$ & 0.199 & $\mathbf{0 . 8 0 1}$ & 0.394 & 0.606 & $\mathbf{0 . 3 9 8}$ & 0.602 \\
$\begin{array}{l}\text { Downward practical support during } \\
\text { parent's visits }\end{array}$ & 0.431 & 0.569 & 0.372 & $\mathbf{0 . 6 2 8}$ & $\mathbf{0 . 8 7 1}$ & 0.129 \\
Estimated class population shares & 0.583 & $\mathbf{0 . 4 1 7}$ & 0.677 & 0.323 & $\mathbf{0 . 7 4 9}$ & 0.252 \\
\hline
\end{tabular}

Data source: SolFam, 2017. Authors' calculation 


\section{Concluding remarks}

The aim of this paper was to provide a broad descriptive image of intergenerational family relationships across distance and national borders. Based on a nation-wide data sample, our statistical analyses provided information about the frequency of various forms of transnational care (Baldassar et al., 2007). We found that different types of care are exchanged regularly or not at all. Building on Morgan's (2011) concepts of family practices and doing family, we studied transnational families from an interactionist perspective. In accordance with this perspective, family relationships and family-like actions are considered to give the meaning of a family that works. Long distance, separation and national frontiers are not obstacles for maintaining and developing intergenerational family relationships. However, we also argue that family practices are not to be taken for granted even in a context of a strong family-oriented system.

Considering the transnational connections that our respondents establish with their emigrated adult children, we also advanced our empirical findings in the framework of transnational care (Baldasar et al., 2007) and care circulation (Baldassar and Merla, 2014). We found that transnational family relationships between non-migrant elderly parents and emigrant adult children are multidirectional and asymmetrical. The family commitment of the younger generation is not just a simple response to the parents' needs and normative obligations, but it is rather fluid and subject to variations. Ageing parents are not to be regarded as frail human beings, dependent on the family help or forgotten family members, but active agents in sustaining and developing family unity even across borders. We also argued that transnational care is subject to variations according to some contextual factors. Needs and opportunities have a great influence for engaging in intergenerational support while the family is spread in different nation-states. Moreover, different meanings can be attached to each type of family interactions and support. Virtual and physical contact is a trigger for emotional assistance but also for other forms of hands-on practical support. Caring from a distance or exchanging gifts has a potential for experiencing a feeling of co-presence (Baldassar, 2008).

Even though some parent-child relationships may lack physical copresence for very long periods of time, the commitments of the individual towards family members are not necessarily lost. We identified numerous arrangements that aim to secure the family well-being and ultimately the family unity even across distance. Separation does not stop the occurrence of actual intergenerational support, but rather it is an evidence of how family arrangements are negotiated. Analysing each type of care separately shows that 
not all individuals are engaged in doing some sorts of family-like actions. We argued that the lack of involvement in one specific form of care does not necessarily indicate the loss of family commitment or broken family bonds. The former analysis was compelling in this sense. Likewise, in a trans-local setting, intergenerational relationships in the context of migration can vary in terms of intensity of the connections or forms of engaged commitments. Also, during a specific period, such family-like actions may not happen at all.

Our research, however, managed to encompass only a small portion of the complex web of transnational family relations. Further studies are needed in order to evidence the broader family network in the context of transnational relationships. Time is also an important factor that offers insights about family backgrounds, individual histories and previous family arrangements (Morgan, 2011). Despite all these limits, we have the confidence that with this study we managed to provide insightful theoretical understandings and to open new research prospects regarding transnational families in the Romanian field of study.

\section{REFERENCES}

Agresti, A. (2002). Categorical data analysis. Second Edition. New York: Wiley.

Baldassar, L. (2001). Visits Home: migration experiences between Italy and Australia. Australia: Melbourne University Press.

Baldassar, L. (2008). Missing Kin and Longing to be Together: Emotions and the Construction of Co-presence in Transnational Relationships. Journal of Intercultural Studies, 29(3): 247-266.

Baldassar, L. (2011). Italian Migrants in Australia and their Relationship to Italy: Return Visits, Transnational Caregiving and the Second Generation. Journal of Mediterranean Studies, 20(2): 255-282.

Baldassar, L. and Merla, L. (2014). Transnational Family Caregiving through the Lens of Circulation. In L. Baldassar and L. Merla, Transnational Families, Migration and the Circulation of Care. Understanding Mobility and Absence in Family Life (324). New York: Routledge.

Baldassar, L., Baldock, C. V. and Wilding, R. (2007). Families Caring Across Borders. Migration, Ageing and Transnational Caregiving. New York: Palgrave Macmillan.

Baykara-Krumme, H. and Fokkema, T. (2018). The impact of migration on intergenerational solidarity types. Journal of Ethnic and Migration Studies.

Bryceson, D. and Vuorella, U. (2002). Transnational Families in the Twenty-First Century. In

D. Bryceson and U. Vuorela, The Transnational Family. New European Frontiers and Global Networks (3-30). Oxford, New York: Berg. 
Ducu, V. (2016). Experiences from "Home" - Belonging to a Transnational Family. Romanian Journal of Population Studies, X (1): 91-104.

Eurostat (2018). News release "4\% of EU citizens of working age live in another EU Member State", 28 May.

http://ec.europa.eu/eurostat/documents/2995521/8926076/3-28052018-AP-

EN.pdf/48c473e8-c2c1-4942-b2a4-5761edacda37 [accessed on 2018, August 17].

Finch, J. (1989). Family Obligations and Social Change. Cambridge, UK: Polity Press.

Finch, J. (2007). Displaying Families. Sociology, Sage Publications, 41(1): 65-81.

Finch, J. and Mason, J. (1993). Negotiating Family Responsibilities. New York: Tavistock/ Routledge.

Gardner, K. and Grillo, R. (2002). Transnational households and ritual: an overview. Global Networks, 2(3): 179-190.

Giddens, A. (1992). The Transformation of Intimacy, Sexuality, Love, and Eroticism in Modern Societies. Cambridge, UK: Polity Press.

Giddens, A. (1994). Beyond Left and Right - the Future of Radical Politics. Cambridge: Polity.

Glick-Schiller, N., Basch, L. and Blanc-Szanton, C. (1992). Towards a Definition of Transnationalism. Introductory Remarks and Research Questions. Annals of the New York Academy of Sciences, 645(1): ix-xiv.

Hărăguș, M. and Telegdi-Csetri, V. (2018). Intergenerational Solidarity in Romanian Transnational Families. In I. Crespi, S. G. Meda and L. Merla (Eds.). Making Multicultural Families in Europe. Gender and Intergenerational Relations (161175). Switzerland: Palgrave Macmillan.

Hărăguș, M., Foldes, I. and Savu, V. (2018). Older Parents in Romania as a Resource for their Migrant Adult Children. In V. Ducu, M. Nedelcu and A. Telegdi-Csetri (Eds.). Childhood and Parenting in Transnational Settings (155-173). Switzerland: Springer.

Karpinska, K. and Dykstra, P. A. (2018). Intergenerational ties across borders: a typology of the relationships between Polish migrants in the Netherlands and their ageing parents. Journal of Ethnic and Migration Studies. https://doi.org/10.1080/1369183X.2018.1485204.

Kilkey, M. and Merla, L. (2014). Situating transnational families' care-giving arrangements: the role of institutional contexts. Global Networks, 14(2): 210-229.

Lazarsfeld, P. and Henry, N. (1968). Latent structure analysis. New York: HoughtonMifflin.

Linzer, D. A. and Lewis, J. (2011). "poLCA: An R Package for Polytomous Variable Latent Class Analysis." Journal of Statistical Software. 42(10): 1-29. http://www.jstatsoft.org/v42/i10.

Linzer, D. A. and Lewis, L. (2013). "poLCA: Polytomous Variable Latent Class Analysis." R package version 1.4 . http://dlinzer.github.com/poLCA.

Litwak, E. and Kulis, S. (1987). Technology, Proximity, and Measures of Kin Support. Journal of Marriage and Family, 49(3): 649-661. 
Madianou, M. (2016). Ambient co-presence: transnational family practices in polymedia environments. Global Networks, 16(2): 183-201.

Madianou, M. and Miller, D. (2012). Polymedia: Towards a new theory of digital media in interpersonal communication. International Journal of Cultural Studies 16(2): 169-187.

Magidson, J. and Vermunt, J. K. (2001). Latent class factor and cluster models, bi-plots and related graphical displays. Sociological Methodology, 31: 223-264.

Magidson, J. and Vermunt, J. K. (2004). Latent class models. In D. Kaplan (Ed.), Handbook of quantitative methods in social science research, Newbury Park, CA: Sage.

McLachlan, G. J. and Krishnan, T. (1997). The EM Algorithm and Extensions. New York: John Wiley \& Sons.

Morgan, D. (1996). Family Connections: An introduction to Family Studies. Cambridge, UK: Polity Press.

Morgan, D. (2011). Rethinking family practices. London: Palgrave Macmillan.

Nedelcu M. (2009). La génération zéro: du sédentaire a l'acteur circulant. Effects de mobilité sur la génération des parents des migrants roumains hautement qualifies à Toronto a l'ère du numérique. In G. Cortes and L. Faret (Eds.). Les Circulations Transnationales: Lire les Turbulences Migratoires Contemporaines (187-198). Paris: Armand Colin.

Nedelcu, M. (2007). « Je passe ma retraite au Canada ». Quand les parents des migrants roumains à Toronto suivent leurs enfants dans la migration. In C. Audebert et E. (Eds.). Ma Mung, Les migrations internationales: enjeux contemporains et questions nouvelles (219-234). Bilbao: Université de Deusto/HumanitarianNet.

Nedelcu, M. and Wyss, M. (2016). 'Doing Family' through ICT-mediated ordinary co-presence: transnational communication practices of Romanian migrants in Switzerland. Global Networks, 16(2): 202-218.

Olwig, K. F. (2002). A respectable livelihood: Mobility and identity in a Caribbean family. In N. N. Sorenson \& K. F. Olwig (Eds.). Work and migration: Life and livelihoods in a globalizing world (85-105). New York: Routledge.

Parsons, T. (1951). The Social System. UK: Routledge \& Kegan Paul Ltd.

Rossi, A. S. and Rossi, P. H. (1990). Of Human Bonding: Parent-child Relations across the Life Course. New York: A. de Gruyter.

Szydlik, M. (2016). Sharing Lives. Adult Children and Parents. London and New York: Routledge Taylor \& FRANCIS Group.

Treas, J. and Mazumdar, S. (2004). Kinkeeping and Caregiving: Contributions of Older People in Immigrant Families. Journal of Comparative Family Studies, 35(1): 105-122.

United Nations, Department of Economic and Social Affairs, Population Division (2017). World Population Prospects. The 2017 Revision. Volume I: Comprehensive Tables. New York: United Nations.

Wilding, R. (2006). 'Virtual' intimacies? Families communicating across transnational contexts. Global Networks, 6(2): 125-142. 


\section{Appendix}

Figure 10.

LC analysis models fit information criterion comparison (visits)

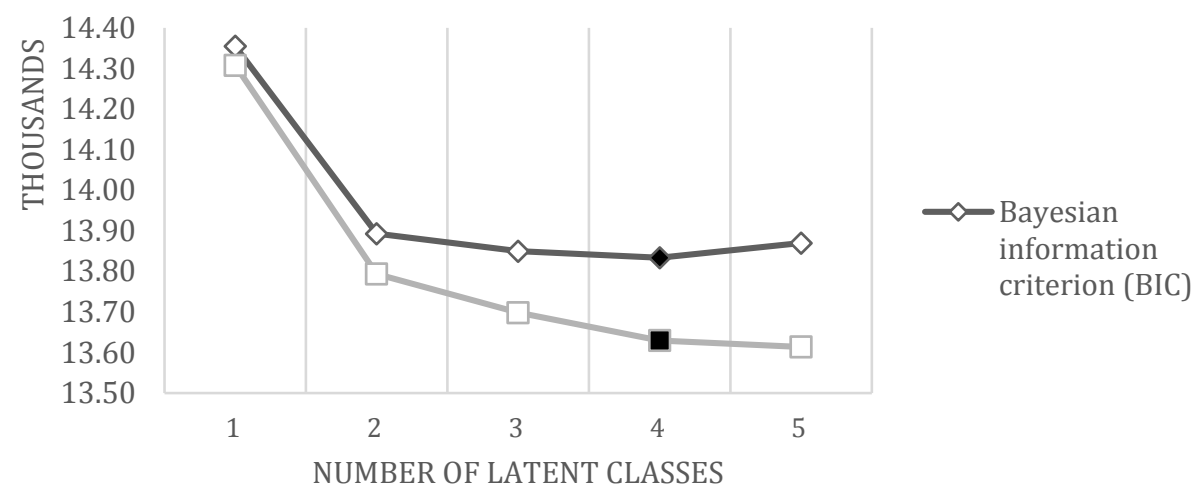

Data source: authors design

Figure 11.

LC analysis models fit information criterion comparison (practical support during visits)

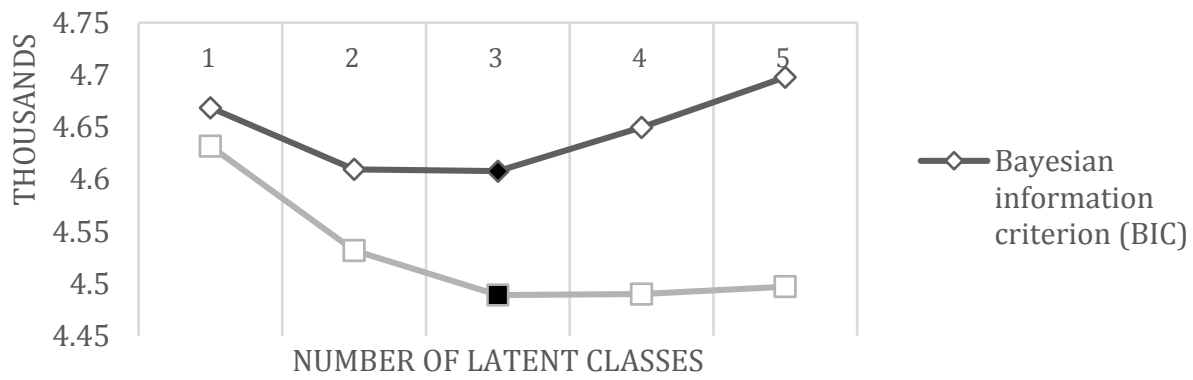

Data source: authors design 